\title{
Correction to: Special issue-before translational medicine: laboratory clinic relations lost in translation? Cortisone and the treatment of rheumatoid arthritis in Britain, 1950-1960
}

\author{
Michael Worboys ${ }^{1}$ (D) Elizabeth Toon ${ }^{1}$
}

Received: 25 January 2019 / Accepted: 1 August 2019 / Published online: 19 December 2019

(C) The Author(s) 2019

\section{Correction to: HPLS (2019) 41:54 \\ https://doi.org/10.1007/s40656-019-0269-7}

The above-mentioned article has been published online on 7 November 2019 as part of topical collection 'Before Translational Medicine: Laboratory Clinic Relations'.

The topical collection title was erroneously merged with the article title. The correct article title reads:

Lost in Translation? Cortisone and the Treatment of Rheumatoid Arthritis in Britain, 1950-1960

Publisher's Note Springer Nature remains neutral with regard to jurisdictional claims in published maps and institutional affiliations.

The original article can be found online at https://doi.org/10.1007/s40656-019-0269-7.

Michael Worboys

michael.worboys@manchester.ac.uk

Elizabeth Toon

elizabeth.toon@manchester.ac.uk

1 Centre for the History of Science, Technology and Medicine (CHSTM), Simon Building,

University of Manchester, Manchester M13 9PL, UK 